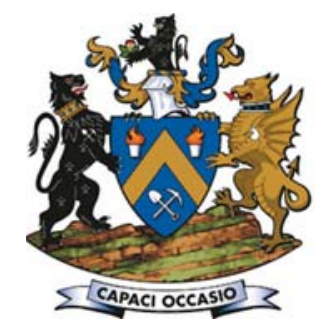

\title{
Characterization of precipitate formed during the removal of iron and precious metals from sulphate leach solutions
}

\author{
by R. Coetzee*, C. Dorfling*, and S.M. Bradshaw*
}

\section{Synopsis}

Nickel sulphate leach solutions produced in the first leaching stage of base metal refineries contain impurities such as iron as well as precious metals $(\mathrm{Rh}, \mathrm{Ru}$, and $\mathrm{Ir})$. Iron precipitation results in sludge formation, which needs to be controlled for efficient operation of downstream nickel recovery processes. Recovery of precious metals from the leach solution is also desired. This study aimed to evaluate the characteristics of the precipitate produced from a nickel sulphate leach solution containing 62.5-89.3 g/L Ni, $2.5-3.57$ $\mathrm{g} / \mathrm{L} \mathrm{Fe}$, and $10 \mathrm{mg} / \mathrm{L}$ of each of $\mathrm{Rh}, \mathrm{Ru}$, and $\mathrm{Ir}$.

Seeded precipitation from ferric-containing solutions resulted in precipitates with a $d_{50}$ particle size of $100.6 \mu \mathrm{m}$, which was two orders of magnitude larger than the reference goethite seed $d_{50}$ particle size of $1.3 \mu \mathrm{m}$. The particle size distributions of the precipitates formed from ferrous solutions were similar to that of the reference goethite seed. The precipitates formed from ferrous-containing solutions at $\mathrm{pH} 2.5$ and at $\mathrm{pH} 4$ had increased micropore areas $\left(72.8 \mathrm{~m}^{2} / \mathrm{g}\right.$ and $87.1 \mathrm{~m}^{2} / \mathrm{g}$, respectively) and decreased external specific surface areas $\left(53.4 \mathrm{~m}^{2} / \mathrm{g}\right.$ and $49.0 \mathrm{~m}^{2} / \mathrm{g}$, respectively) compared to the goethite reference material (micropore surface area of 66.2 $\mathrm{m}^{2} / \mathrm{g}$ and external surface area of $64.8 \mathrm{~m}^{2} / \mathrm{g}$ ). For ferric-containing solutions at pH 2.5, a decline in specific surface area from $131.0 \mathrm{~m}^{2} / \mathrm{g}$ to between 82.0 $\mathrm{m}^{2} / \mathrm{g}$ and $100.6 \mathrm{~m}^{2} / \mathrm{g}$ was caused by aggregation and molecular growth inside micropores. Instantaneous iron precipitation from ferric solutions at $\mathrm{pH} 4$ resulted in an increased Brunauer-Emmett-Teller (BET) surface area of 156.5 $\mathrm{m}^{2} / \mathrm{g}$ due to poor ordering of crystal structure and a more amorphous surface structure.

Iron oxide phases present in the precipitates had elemental compositions similar to ferrihydrite and schwertmannite. Sulphate inclusion was more prominent during the rapid precipitation from ferric solutions than during precipitation from ferrous solutions. The precipitate formed at $\mathrm{pH} 2.5$ was overall more crystalline than the precipitate formed at $\mathrm{pH} 4.0$; nickel entrainment also increased with an increase in $\mathrm{pH}$. Rhodium- and rutheniumcontaining species were finely dispersed throughout the iron phases in the precipitates. Iridium precipitated primarily without the inclusion of iron or other precious metals; particles consisting of iridium (50-80 wt\%), chloride, and oxygen were formed.

\section{Keywords}

base metals refining, nickel sulphate leach solution, iron precipitation, surface area, porosity, platinum group metals.

\section{Introduction}

The nickel sulphate solution produced in the first leaching stage in base metal refineries in the platinum industry can be treated by evaporation and crystallization to produce nickel sulphate hexahydrate crystals. At a specific base metal refinery, sludge formation within the heat exchangers and the holding tanks has been observed; this is believed to be due to precipitation of metal impurities in the stream. Iron is the most abundant impurity in the leach solution and in the sludge, while 'other precious metals' (OPMs, namely $\mathrm{Ru}, \mathrm{Rh}$, and Ir) are also present.
Sludge formation needs to be controlled to allow more efficient operation of the nickel crystallization section, while it can also serve as a mechanism for recovery of other precious metals that are present in the leach solution. The objective of this study was to investigate the precipitation behaviour of iron and other precious metals from the nickel sulphate leach solution at different $\mathrm{pH}$ values, temperatures, iron oxidation states, seeding conditions, and metal concentrations. The investigation focused specifically on the characteristics of the precipitate formed under different precipitation conditions. Solids characterization techniques that were used include X-ray diffraction (XRD), particle size distribution (PSD), Brunauer-Emmett-Teller (BET) surface area analysis, and scanning electron microscopy (SEM) with energy dispersive X-ray spectroscopy (EDS). Knowledge about the characteristics, structure, and composition of the precipitate formed at different conditions can assist in optimal management of sludge formation on site.

\section{Iron precipitation}

The precipitation of iron from acidic solutions proceeds primarily by hydrolysis of ferric, which leads to the formation of complexed iron hydroxides and, subsequently, solid precipitates. For precipitation of iron from ferrous-containing solutions, the first step would entail oxidation of ferrous to ferric. This oxidation step, presented in Equation [1], is typically rate-limiting when precipitation is performed below $150^{\circ} \mathrm{C}$ (Singer and Stumm, 1970). At higher temperatures, oxygen solubility may become rate-limiting, depending on solution chemistry (Lowson, 1982). Subsequent hydrolysis proceeds according to Equation [2] or, if the iron concentration

* Department of Process Engineering, Stellenbosch University, South Africa.

(c) The Southern African Institute of Mining and Metallurgy, 2017. ISSN 2225-6253. This paper was first presented at the Hydrometallurgy Conference 2016 'Sustainable Hydrometallurgical Extraction of Metals', 1-3 August 2016, Belmont Mount Nelson Hotel, Cape Town. 


\section{Characterization of precipitate formed during the removal of iron}

exceeds $10^{-3} \mathrm{M}$, by means of dimerization shown in Equation [3] (Dutrizac, 1980).

$$
\begin{aligned}
& 4 \mathrm{Fe}^{2+}+\mathrm{O}_{2(\mathrm{aq})}+4 \mathrm{H}^{+} \rightarrow 4 \mathrm{Fe}^{3+}+2 \mathrm{H}_{2} \mathrm{O} \\
& \mathrm{Fe}\left(\mathrm{OH}_{2}\right)_{6}{ }^{3+} \rightarrow \mathrm{Fe}(\mathrm{OH}) n\left(\mathrm{OH}_{2}\right)_{6-n}{ }^{3-n}+n \mathrm{H}^{+} \\
& 2 \mathrm{Fe}^{3+}+2 \mathrm{H}_{2} \mathrm{O} \rightarrow \mathrm{Fe}_{2}(\mathrm{OH})_{2}{ }^{4+}+2 \mathrm{H}^{+}
\end{aligned}
$$

The hydroxyl complexes formed according to Equation [3] undergo polymerization to form longer iron hydroxyl compounds, which could incorporate other ligands and which serve as precursor for iron oxide and iron hydroxide precipitates. Jiang and Lawson (2006), for example, reported that substitution of hydroxide with sulphate ligands at low $\mathrm{pH}$ values and high sulphate concentrations results in the formation of sulphur-containing iron precipitates. Bigham et al. (1996) reported that some of the sulphur in ferrihydrite compounds may not be structurally incorporated, but rather adsorbed onto the surface of the iron species. In these cases, sulphur is considered an anionic impurity. The direct formation of iron sulphate complexes, which could serve as intermediate in the formation of iron sulphate precipitates, is also possible via Equations [4] and [5] (Cornell and Schwertmann, 2003).

$$
\begin{aligned}
& \mathrm{Fe}^{3+}+\mathrm{SO}_{4}{ }^{2-} \rightarrow \mathrm{Fe}\left(\mathrm{SO}_{4}\right)^{+} \\
& \mathrm{Fe}\left(\mathrm{SO}_{4}\right)^{+}+\mathrm{SO}_{4}{ }^{3-} \rightarrow \mathrm{Fe}\left(\mathrm{SO}_{4}\right)_{2}^{-}
\end{aligned}
$$

The type of precipitate that forms depends on the leach solution conditions. According to Cornell and Schwertmann (2003), rapid hydrolysis results in the formation of ferrihydrite, while slow hydrolysis at elevated temperatures will lead to the formation of akaganéite or its sulphate derivative, schwertmannite $\left(\mathrm{Fe}_{8} \mathrm{O}_{8}(\mathrm{OH})_{x}\left(\mathrm{SO}_{4}\right)_{y}\right)$. Commercial iron precipitation processes are designed to form one of the thermodynamically most stable species. Goethite $(\alpha-\mathrm{FeOOH})$ and haematite $\left(\alpha-\mathrm{Fe}_{2} \mathrm{O}_{3}\right)$ are the thermodynamically most stable iron hydroxide and iron oxide precipitates, respectively. In terms of iron sulphate precipitates, jarosite is the thermodynamically most stable precipitation product.

Seeding of growth medium is an important design parameter as it aims to provide a growth surface for targeted growth of certain iron phases without the requirement for nucleation. The mechanism by which precipitation then proceeds involves transport of the dissolved species to the surface, adsorption on the surface, and incorporation into the crystal. Incorporation in the crystal structure can be a result of reactions such as dehydration or dehydroxylation (Cornell and Schwertmann, 2003). Cation substitution is also possible, whereby foreign cations replace iron in the crystal structure; the likelihood of cation substitution occurring is determined by how closely the valence and ionic radius of the foreign cation resembles that of the ferric ion (Goldschmidt, 1937). Other mechanisms for co-precipitation include direct precipitation (by, for example, hydrolysis) and entrainment.

\section{Experimental}

\section{Materials}

The precipitation experiments were performed using three different synthetic nickel sulphate leach solutions. The compositions of the 'low' and 'high' solutions reported in Table I were based on the typical range of metal concentrations in the industrial leach solutions; some precipitation tests were also performed on synthetic solutions containing only iron and precious metals (labelled OPM in Table I) in order to develop a better understanding of the precious metals' precipitation behaviour. The synthetic solutions were prepared using the reagents listed in Table II. Goethite seed material $(\alpha-\mathrm{FeOOH}, 30-63 \% \mathrm{Fe})$ was supplied by Sigma Aldrich.

\section{Equipment}

The precipitation tests were performed in closed $1.6 \mathrm{~L}$ glass vessels. The solution was stirred using magnetic stirrers set to a constant stirring speed of $600 \mathrm{r} / \mathrm{min}$, and vortex formation was minimized by means of four epoxy-coated baffles inserted in the vessel. Agitation speeds between 300 $\mathrm{r} / \mathrm{min}$ and $700 \mathrm{r} / \mathrm{min}$ were assessed; it was found that agitation at a rate of $600 \mathrm{r} / \mathrm{min}$ was sufficient to agitate solids, mix reagents with the solution, and ensure an evenly distributed temperature profile. A Pt-100 thermocouple connected to a hotplate with feedback control was used to control the temperature to within $2^{\circ} \mathrm{C}$ of the temperature setpoint. The solution $\mathrm{pH}$ was controlled using a Eutech Alpha pH 560 controller with the output connected to a solenoid valve in the outlet of a burette filled with a sodium hydroxide solution, which was gravity-fed to the reaction vessel as required. A Liebig condenser connected to the vessel lid was used to minimize evaporation losses. The temperature and

\section{Table II \\ Reagents used for preparation of the synthetic leach solutions}

\begin{tabular}{|l|c|c|c|}
\hline Metal & Source & Grade & Purity \\
\hline $\mathrm{Ni}$ & $\mathrm{NiSO}_{4} \cdot 6 \mathrm{H}_{2} \mathrm{O}$ & Analytical Reagent & $99 \%$ \\
$\mathrm{Cu}$ & $\mathrm{CuSO}_{4} \cdot 5 \mathrm{H}_{2} \mathrm{O}$ & Analytical Reagent & $98.5 \%$ \\
$\mathrm{Fe} 2+$ & $\mathrm{FeSO}_{4} \cdot 7 \mathrm{H}_{2} \mathrm{O}$ & Analytical Reagent & $98 \%$ \\
$\mathrm{Fe}^{3+}$ & $\mathrm{Fe}_{2}\left(\mathrm{SO}_{4}\right)_{3} \cdot \mathrm{xH}_{2} \mathrm{O}$ & Technical & $97 \%$ \\
$\mathrm{Co}$ & $\mathrm{CoSO}_{4} \cdot 7 \mathrm{H}_{2} \mathrm{O}$ & Analytical Reagent & $99 \%$ \\
$\mathrm{Rh}$ & $\mathrm{RhCl}_{3} \cdot \mathrm{xH}_{2} \mathrm{O}$ & Not specified & $38-40 \% \mathrm{Rh}$ \\
$\mathrm{Ru}$ & $\mathrm{RuCl}_{3} \cdot \mathrm{xH}_{2} \mathrm{O}$ & Reagent & $38-42 \% \mathrm{Ru}$ \\
$\mathrm{Ir}$ & $\mathrm{ICl}_{3} \cdot \mathrm{xH}_{2} \mathrm{O}$ & Reagent & Not given \\
$\mathrm{As}$ & $\mathrm{As}_{2} \mathrm{O}_{3}$ & Analytical Reagent & $>99.8 \%$ \\
$\mathrm{Na}$ & $\mathrm{NaOH}_{-}$ & Analytical Reagent & $>99 \%$ \\
& $\mathrm{H}_{2} \mathrm{SO}_{4}$ & Analytical Reagent & $>99 \%$ \\
\hline
\end{tabular}

Table I

Metal concentrations in the respective synthetic leach solutions

\begin{tabular}{|l|c|c|c|c|c|c|c|c|}
\hline Total metals & Ni (g/L) & Co (mg/L) & Fe (mg/L) & Cu (mg/L) & As (mg/L) & Rh (mg/L) & $\mathbf{R u ~ ( m g / L ) ~}$ & $\mathbf{I r}(\mathbf{m g} / \mathbf{L})$ \\
\hline Low & 62.5 & 650 & 2500 & 50 & 65 & 10 & 10 \\
High & 89.3 & 930 & 3570 & 70 & 93 & 14 & 10 \\
OPM & - & - & 2500 & - & - & 10 & 10 \\
\hline
\end{tabular}




\section{Characterization of precipitate formed during the removal of iron}

pH set-points for the respective tests are listed in Table III; the ranges of temperatures, $\mathrm{pH}$ values and metal concentrations were selected to correspond with the typical plant operating conditions.

\section{Procedure}

A working volume of $500 \mathrm{~mL}$ was used for all experiments. The solution was prepared by adding $\mathrm{NaOH}$ to $300 \mathrm{~mL}$ demineralized water. The amount of $\mathrm{As}_{2} \mathrm{O}_{3}$ required to achieve the As concentrations specified in Table I was dissolved in the alkaline solution before $\mathrm{H}_{2} \mathrm{SO}_{4}$ was added to lower the $\mathrm{pH}$ to 3 . At this $\mathrm{pH}$, the $\mathrm{Ni}, \mathrm{Co}, \mathrm{Cu}$, and precious metal salts were added. The solution was then diluted to close to $500 \mathrm{~mL}$ and acidified to $\mathrm{pH} 1.7$ before iron salts were added. Once all the metal salts had dissolved, the solution volume was made up to $500 \mathrm{~mL}$. The solution was added to the glass vessel, agitation was started, and temperature control initiated. Once the set-point temperature had been reached, the initial sample was taken and the seed material and neutralizing agent added immediately afterwards. The solution was then left for a period of 6 hours, during which $4.5 \mathrm{~mL}$ liquid samples were taken intermittently (at 2, 15, 30, $60,90,120,180,240$, and 360 minutes) to monitor metal precipitation over time. The solution that remained after six hours was filtered, and the solids residue washed with water and dried for analysis.

The precipitation tests were performed at different $\mathrm{pH}$ values, iron oxidation states, total metal concentrations, temperatures, and seeding conditions. A summary of the conditions investigated and the corresponding analyses is presented in Table III.

\section{Analytical techniques}

\section{$X$-ray diffraction}

The precipitates, already in a finely powdered form, were analysed using a Bruker AXS D8 Advance diffractometer; $\mathrm{Cu}$ $K$ radiation with a position sensitive Vantec-1 detector was utilized. The detected peaks were normalized and matched to the International Centre for Diffraction Data (ICDD) powder detection file database of 1998. Data evaluation was done with Bruker's EVA software. The step time, step size, and counting times were varied in order to yield good statistics. A tube voltage of $40 \mathrm{kV}$ and current of $40 \mathrm{~mA}$ were applied.

Particle size distribution

Particle size distribution analysis was done by screening agglomerate samples with a pass size of $106 \mu \mathrm{m}$; the particle size distribution of the passing sample was determined using a Saturn DigiSizer 5200. The screening step was done to improve the repeatability of PSD analyses. With unscreened samples, the larger particle fraction gradually decreased in size and the smaller size fractions gradually increased with sequential tests. Water submersion and ultrasonic treatment alone did not adequately separate the solids into unit particles. A refraction index of 2.268 for goethite and 1.715 for jarosite were used. A flow rate of $12 \mathrm{~L} / \mathrm{min}$ with 1 minute circulation time and 1 minute ultrasonic treatment time at $60 \%$ intensity was employed. The laser strength was $1.88 \mathrm{eV}$. Samples were pulped prior to analysis, and analysis was conducted with and without ultrasonic treatment.

\section{BET surface area}

Brunauer-Emmett-Teller (BET) theory surface area analysis with nitrogen gas was performed with a Micromeritics 3Flex 1.02. Subsequently, Harkins and Jura adsorption isotherm tplots were calculated to determine the external surface area and the micropore area. Cornell and Schwertmann (2003) reported that crystal lattice level transformation might occur during BET surface area work at elevated outgassing temperatures. Dehydroxylation of ferric oxyhydroxides may also occur, causing slit-shaped micropores to be formed.

In this study, outgassing was initially performed at low temperatures to prevent crystal lattice transformation. Outgassing was performed overnight at a temperature of $90^{\circ} \mathrm{C}$ followed by outgassing overnight at $50^{\circ} \mathrm{C}$. At low outgassing temperatures uncharacteristically low surface area $\left(<10 \mathrm{~m}^{2} / \mathrm{g}\right)$ precipitates were reported, which indicated that outgassing at low temperature might not have removed all adsorbed gas. Thereafter, the standard outgassing temperature of $250^{\circ} \mathrm{C}$ was utilized. With reference goethite used for seeding, a BET surface area of $131.01 \mathrm{~m}^{2} / \mathrm{g}$ was reported after 6 hours' outgassing at $250^{\circ} \mathrm{C}$. The same sample was then outgassed for a further 17 hours at $250^{\circ} \mathrm{C}$, which resulted in a BET surface area of $131.07 \mathrm{~m}^{2} / \mathrm{g}$. This confirmed the accuracy and reproducibility of the values. The remaining samples were outgassed at $250^{\circ} \mathrm{C}$ for 17 hours.

\section{Scanning electron microscopy}

Precipitates were analysed by scanning electron microscopy (SEM) with quantitative energy-dispersive X-ray spectroscopy (EDS) using a Zeiss MERLIN Field Emission Gun (FEG) instrument. The nickel, cobalt, iron, copper,

\begin{tabular}{|c|c|c|c|c|c|c|c|c|}
\hline $\mathrm{pH}$ & Fe oxidation & Composition & Temperature $\left({ }^{\circ} \mathrm{C}\right)$ & Seeding & BET & PSD & XRD & SEM \\
\hline $\begin{array}{l}4.0 \\
2.5 \\
2.5 \\
4.0 \\
2.5 \\
4.0 \\
4.0 \\
4.0 \\
4.0 \\
4.0 \\
2.5 \\
4.0 \\
2.5\end{array}$ & $\begin{array}{l}2+ \\
2+ \\
3+ \\
3+ \\
3+ \\
3+ \\
2+ \\
2+ \\
3+ \\
3+ \\
2+ \\
2+ \\
3+\end{array}$ & $\begin{array}{l}\text { Low } \\
\text { Low } \\
\text { Low } \\
\text { Low } \\
\text { High } \\
\text { High } \\
\text { Low } \\
\text { High } \\
\text { High } \\
\text { OPM } \\
\text { OPM } \\
\text { OPM } \\
\text { OPM }\end{array}$ & $\begin{array}{l}70 \\
70 \\
70 \\
90 \\
90 \\
90 \\
70 \\
90 \\
90 \\
90 \\
90 \\
90 \\
90\end{array}$ & $\begin{array}{c}\text { Goethite } \\
\text { Goethite } \\
\text { Goethite } \\
\text { Goethite } \\
\text { Goethite } \\
\text { Goethite } \\
\text { None } \\
\text { None } \\
\text { None } \\
\text { None } \\
\text { None } \\
\text { None } \\
\text { None }\end{array}$ & $\begin{array}{l}x \\
x \\
x \\
x \\
x\end{array}$ & $\begin{array}{l}x \\
x \\
x \\
x \\
x\end{array}$ & $\begin{array}{l}x \\
x \\
x \\
x \\
x \\
x\end{array}$ & $\begin{array}{l}x \\
x \\
x\end{array}$ \\
\hline
\end{tabular}




\section{Characterization of precipitate formed during the removal of iron}

sulphur, oxygen, chloride, ruthenium, rhodium, iridium, and arsenic contents of precipitates were determined by EDS using an Oxford Instruments ${ }^{\circledR}$ XMax $20 \mathrm{~mm}^{2}$ detector and Oxford INCA software. Beam conditions during the quantitative analyses on the MERLIN FEG SEM were $20 \mathrm{kV}$ and $16 \mathrm{nA}$, with a working distance of $9 \mathrm{~mm}$. The mineral counting time was 15 seconds live-time for EDS. A cobalt standard was used for standardization and verification of the analyses. The system is designed to perform high-resolution imaging concurrently with quantitative analysis, with errors ranging from $\pm 0.1 \mathrm{wt} \%$ to $0.6 \mathrm{wt} \%$ on the major elements using EDS. Compositional data reported are averaged from at least three corresponding data points.

Backscattered electron (BSE) detector images were utilized to qualitatively define different precipitate phases. Secondary electron (SE) detector images provided surface morphology analysis, and visual observation of the precipitates. Composition maps were drawn, but were largely ineffective due to the predominance of iron and the little deviations seen in samples.

\section{Results and discussion}

\section{Particle size distribution}

The average particle size distributions (PSDs) for three samples precipitated at each of the respective sets of conditions are shown in Figure 1. The reference goethite sample had a $d_{50}$ particle size of $1.3 \mu \mathrm{m}$; the peak at $12.7 \mu \mathrm{m}$ was due to agglomeration. From Figure $1 a$, it is evident that particle growth occurred during precipitation from ferric solutions: the particles had a negative skew distribution with a $d_{50}$ of $100.6 \mu \mathrm{m}$. The precipitation on goethite seed led to growth and agglomeration that did not disperse during pulping or ultrasonic treatment. Comparison of the results obtained for the low and high metal concentration solutions in Figure 1a reveals an increased volume fraction between $2 \mu \mathrm{m}$ and $8 \mu \mathrm{m}$ for the high metal concentration experiment. This could be ascribed to the fact that the high degree of supersaturation associated with this experiment resulted in precipitation by spontaneous primary nucleation and particle growth $(2-8 \mu \mathrm{m})$ in addition to precipitation by growth of seed material (peak around $100 \mu \mathrm{m}$ ), which was the main precipitation mechanism for the low-concentration experiments.

The percentage iron precipitation achieved for the solutions containing ferrous were generally low. This was expected, given the fact that ferrous hydrolysis generally occurs to a noticeable extent only at $\mathrm{pH}$ values of 6 or higher, depending on the ferrous concentration. In the two tests for which solid residues were collected and analysed, the iron precipitation was $8.7 \%$ and $1.3 \%$ at $\mathrm{pH} 4$ and $\mathrm{pH} 2.5$, respectively. It was thus expected that there would be limited particle growth. The PSDs shown in Figure $1 \mathrm{~b}$ indicate that there was no particle growth in these experiments. The agreement between the PSD of the reference goethite and that of the residue from these experiments is evident. The consistency of goethite seed in ferrous experiments therefore acts as a control, supporting the growth observed in ferric precipitation reactions.

The PSD for the iron precipitated without goethite seed is presented in Figure 2. This sample was not sieved to $106 \mu \mathrm{m}$ prior to analysis with the Saturn DigiSizer 5200 .

Approximately $48 \%$ of the particles in the sample were larger than $106 \mu \mathrm{m}$, although this could to some extent be attributed to agglomerate formation. Even though the particles were larger than in the seeded experiments, the filterability of the precipitate was significantly worse than that from seeded experiments.

\section{BET surface area}

The BET surface areas obtained for the respective precipitates are listed in Table IV. Micropores are molecular-size pores sized less than $20 \AA$, mesopores range between $20 \AA$ and $500 \AA$, and macropores are larger than $500 \AA$ (Rouquerol et al., 1994). The micropore surface area and external surface area can be considered to be two different active sites available for particle growth and adsorption. A decline in micropore surface area suggests molecular growth occurring on the corresponding active sites, while a decrease in external surface area can be ascribed to agglomeration.

The precipitate produced without seeding from the ferric-containing OPM solution had a BET surface area of
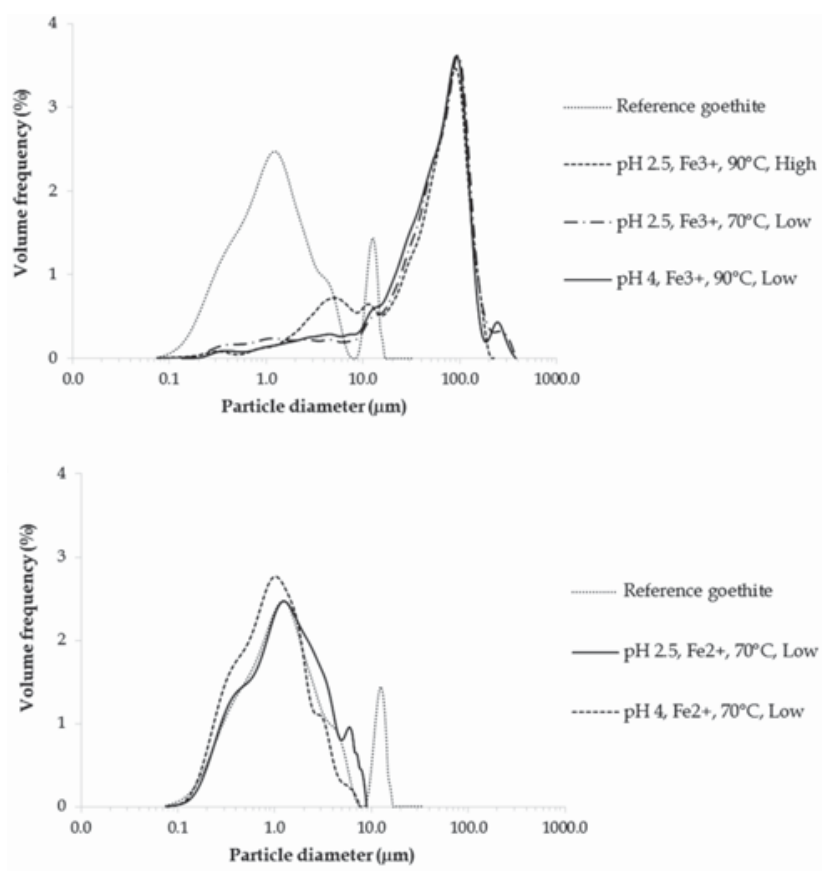

Figure 1-Particle size distributions for precipitates formed during seeded precipitation from (a) ferric solutions, and (b) ferrous solutions. 'High' and 'Low' in the legends refer to the metal concentrations defined in Table I

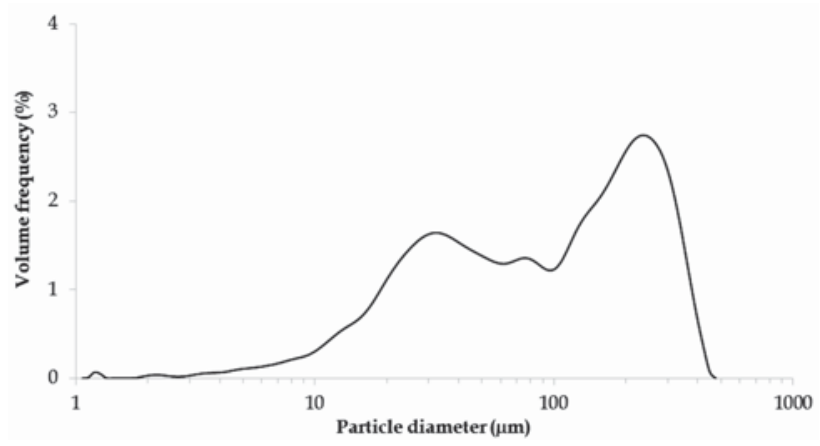

Figure 2-Particle size distribution for precipitate formed during unseeded precipitation from a ferric-containing OPM solution at $\mathrm{pH} 4$ and $90^{\circ} \mathrm{C}$ 


\section{Characterization of precipitate formed during the removal of iron}

\begin{tabular}{|c|c|c|c|c|c|c|c|}
\hline \multicolumn{8}{|c|}{ Table IV } \\
\hline \multicolumn{8}{|c|}{ BET surface areas measured for the precipitates formed at the respective conditions } \\
\hline $\mathrm{pH}$ & $\mathrm{Fe}$ oxidation & $\begin{array}{c}\mathrm{T} \\
\left({ }^{\circ} \mathrm{C}\right)\end{array}$ & Composition & $\begin{array}{c}\text { Fe precipitation } \\
(\%)\end{array}$ & $\begin{array}{l}\text { BET surface area } \\
\qquad\left(\mathrm{m}^{2} / \mathrm{g}\right)\end{array}$ & $\begin{array}{l}\text { Micropore surface area } \\
\qquad\left(\mathrm{m}^{2} / \mathrm{g}\right)\end{array}$ & $\begin{array}{l}\text { External surface area } \\
\qquad\left(\mathrm{m}^{2} / \mathrm{g}\right)\end{array}$ \\
\hline 4.0 & $3+$ & $\begin{array}{l}90 \\
\text { Reference goethite }\end{array}$ & OPM & $\begin{array}{c}100 \% \\
\mathrm{n} / \mathrm{a}\end{array}$ & $\begin{array}{c}215.8 \pm 1.9 \\
131.0 \pm 2.0\end{array}$ & $\begin{array}{c}0.0 \\
66.2\end{array}$ & $\begin{array}{r}216.6 \\
64.8\end{array}$ \\
\hline 2.5 & $3+$ & 90 & High & $75 \%$ & $100.6 \pm 0.5$ & 44.3 & 56.3 \\
\hline 2.5 & $3+$ & 70 & Low & $69 \%$ & $82.0 \pm 0.2$ & 43.9 & 38.1 \\
\hline 4.0 & $3+$ & 90 & Low & $100 \%$ & $156.5 \pm 0.8$ & 64.0 & 92.6 \\
\hline 2.5 & $2+$ & 70 & Low & $1 \%$ & $126.2 \pm 1.5$ & 72.8 & 53.4 \\
\hline 4.0 & $2+$ & 70 & Low & $9 \%$ & $136.1 \pm 1.2$ & 87.1 & 49.0 \\
\hline
\end{tabular}

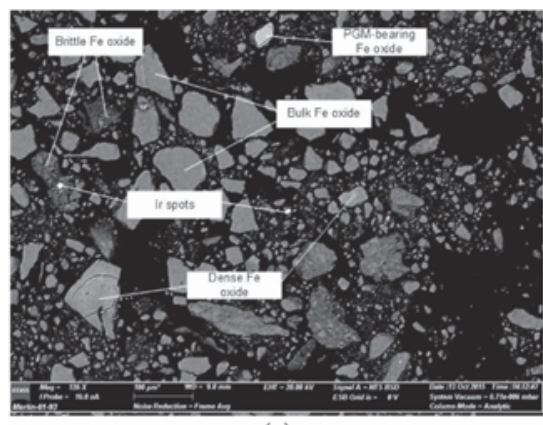

(a)

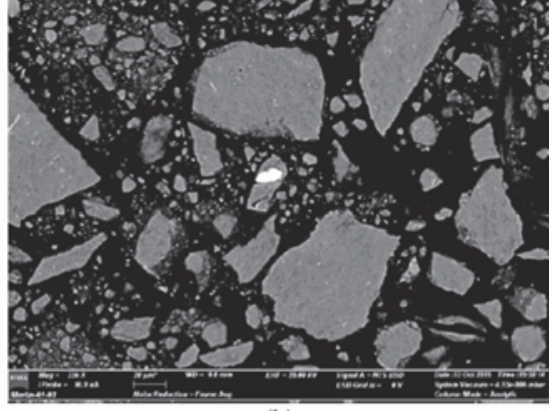

(b)

Figure 3-SEM (a) bulk and (b) magnified image of the precipitate produced from ferrous-containing $\mathrm{OPM}$ solution at $\mathrm{pH} 2.5$ and $90^{\circ} \mathrm{C}$

$215.8 \mathrm{~m}^{2} / \mathrm{g}$. This precipitate was characterized as predominantly ferrihydrite, as discussed in the following section on SEM results. The expected surface areas of ferrihydrite compounds vary between $100 \mathrm{~m}^{2} / \mathrm{g}$ and $700 \mathrm{~m}^{2} / \mathrm{g}$ (Cornell and Schwertmann, 2003). The precipitation was generally rapid, and the resulting poorly ordered crystal structure contributed to the relatively high surface area compared to the reference goethite. As was observed from the PSD for this precipitate (Figure 2), the ferrihydrite formed agglomerated particles. The fact that no micropore surface area was measured for the precipitate suggested that the pores in the agglomerates were sufficiently large to be classified as external surface area rather than micropores.

The reference goethite sample had a BET surface area of $131.0 \mathrm{~m}^{2} / \mathrm{g}$. Goethite surface area is considered high in the range of $80 \mathrm{~m}^{2} / \mathrm{g}$ to $150 \mathrm{~m}^{2} / \mathrm{g}$ (Cornell and Schwertmann, 2003). The surface area was equally distributed between micropores and the external surface. The total BET surface areas of the precipitates produced from ferrous solutions were comparable with that of the reference goethite. The distribution did, however, indicate increased micropore surface area and decreased external surface area. The external surface area decrease implies that agglomeration occurred. The increased micropore surface area could be ascribed to a combination of chemical weathering of the goethite particles and formation of micropores due to growth on the external surface.

The total BET surface areas of the precipitate produced from solutions containing ferric decreased in the case of $\mathrm{pH}$ 2.5 , due to a decrease in the micropore surface area as well as the external surface area of the particles. The solution with the higher total metal concentration was seeded with relatively more seed to maintain a 2:1 seed to Fe in solution ratio. The decrease in the total surface area could be ascribed to aggregation at pH 2.5. The micropore surface area declined by a third, but not to the extent of unseeded precipitated iron, where no micropore surface area was recorded.

The precipitate produced from the ferric-containing solution at $\mathrm{pH} 4$ had a higher BET surface area than the reference goethite, with an increase in the external surface area being responsible for the increase in the total surface area. This could be ascribed to the rapid iron precipitation observed at $\mathrm{pH} 4$, which resulted in poor ordering of crystal structure.

\section{SEM and XRD}

\section{Precipitates formed from 'OPM' solutions}

Figure 3 presents the backscattered SEM image of the precipitate formed from a ferrous-containing OPM solution during unseeded precipitation at $\mathrm{pH} 2.5$ and $90^{\circ} \mathrm{C}$. Three distinct iron oxide phases were observed, namely the bulk, brittle, and dense phases. Individual iridium phases also occurred. These iridium phases were very dense and could be readily observed, defined as 'Ir spots' in Figure 3a. In Figure $3 b$, the iridium phase in the centre possibly acted as growth surface for the bulk iron oxide phase. This observation was consistent for iridium in all other samples: iridium was either present as independent particles, or was enveloped within the bulk iron oxide phase. Ruthenium and rhodium were only observed in varying low quantities as part of iron oxide phases.

The elemental compositions of the phases identified in Figure 3 are summarized in Table V, with the bulk and brittle iron oxide phases having similar compositions. The dense phase had the highest iron content and incorporated the least anionic impurities (sulphate and chloride). The three iron phases corresponded stoichiometrically with the structural formulae of schwertmannite and ferrihydrite. The iridium 


\section{Characterization of precipitate formed during the removal of iron}

Table $\mathrm{V}$

Elemental compositions of phases identified in Figure 3

\begin{tabular}{|l|c|c|c|c|c|c|}
\hline & Fe (wt\%) & $\mathbf{O}(\mathbf{w t} \%)$ & $\mathbf{S ~ ( w t \% )}$ & $\mathbf{C l}(\mathbf{w t} \%)$ & $\mathbf{R u}(\mathbf{w t} \%)$ & $\mathbf{R h}(\mathbf{w t} \%)$ \\
\hline Bulk Fe oxide & $54.9 \pm 0.4$ & $40.4 \pm 0.1$ & $3.7 \pm 0.1$ & $0.5 \pm 0.1$ & \\
Brittle Fe oxide & $53.4 \pm 0.7$ & $40.7 \pm 0$ & $4.1 \pm 0.1$ & $1 \pm 0.2$ & \\
Dense Fe oxide & $58.1 \pm 0.2$ & $39.3 \pm 0.1$ & $2.5 \pm 0.2$ & $23.3 \pm 1.8$ & \\
Ir phase & $2 \pm 0.5$ & $13.1 \pm 0.1$ & & \\
OPM-bearing Fe oxide & $44.6 \pm 1$ & $48.7 \pm 0.4$ & $3.1 \pm 0.7$ & $0.5 \pm 0.3$ & $0.7 \pm 0.2$ & $2.4 \pm 0.2$ \\
\hline
\end{tabular}

phases were approximately $5 \mu \mathrm{m}$ in size; the most abundant iridium phase consisted of $60.5 \%$ iridium, $23.3 \%$ chloride, and $13.1 \%$ oxygen.

Increasing the $\mathrm{pH}$ from 2.5 to 4 resulted in the formation of a heterogeneous iron precipitate from ferrous-containing OPM solution, as shown in Figure 4. Three distinctly different phases were observed, namely dense, medium-dense, and bulk iron oxide. With the higher addition of a strong neutralizing agent, local regions with high $\mathrm{pH}$ were more likely to form, which could have resulted in the formation of the dense phases; this, in turn, acted as growth medium for the medium-dense and bulk iron oxide phases.

The elemental compositions of defined phases are reported in Table VI. Dense iron oxide phases, of $5 \mu \mathrm{m}$ particle size on average, did not contain any sulphate or chloride ions. The medium-dense and bulk iron oxide phases contained the same quantities of sulphate and chloride ions. The presence of sulphate and chloride ions in the mediumdense and bulk phases suggested that anionic impurities were included in the crystal lattices of these phases, which might have been caused by poorly ordered crystal lattices. The bulk iron oxide phase indicated the consistent presence of OPMs. All three phases were most likely variants of ferrihydrite.

The lowest density phase was an unusual location for OPMs considering their high molecular weights. Its dispersed nature in the bulk iron phase indicated that initial iron precipitation was faster and aggregation could have captured the OPM solids during precipitation.

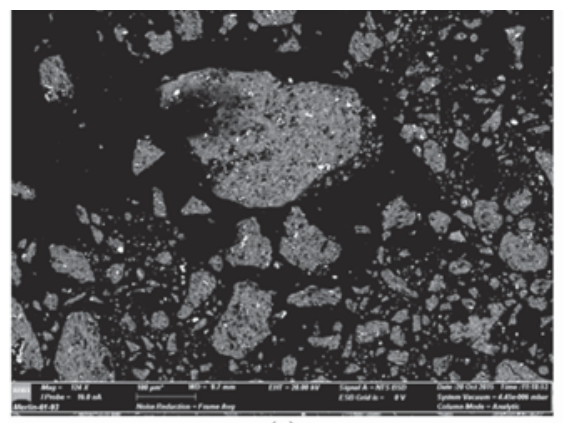

(a)
In the case of the precipitate formed from OPM solutions containing ferric, several phases were identified on the SEM images (Figure 5). Two homogeneous phases were observed, one of medium density (bulk iron oxide) and the other of low density. A heterogeneous medium-density iron oxide phase, which contained small interlocked high density phases, was also present.

The elemental compositions of phases defined in Figure 5 are summarized in Table VII. In contrast to the precipitate produced from the ferrous solutions, appreciably more sulphate was incorporated in the denser phases, with declining iron content as the density increased. The greater amount of sulphate suggests schwertmannite formation. Small amounts of sodium were also structurally incorporated, which might imply the presence of minor amounts of jarosite.

XRD analyses of the precipitates produced from ferriccontaining OPM solutions could not characterize the iron oxide using conventional peak-matching. The diffractogram was compared to published results (Yu, Park, and Kim, 2002; Cornell and Schwertmann, 2003; Schwertmann and Carlson, 2005; Das, Hendry, and Essilfie-Dughan, 2011;

Bazilevskaya, Archibald, and Martínez, 2012). It was deduced that the precipitate was a hybrid between poorly crystalline goethite and schwertmannite, but might also have contained ferrihydrite.

\section{Unseeded precipitates}

SEM images of the precipitate formed by unseeded

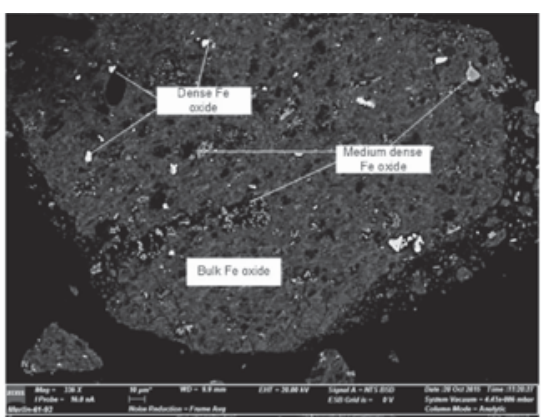

(b)

Figure 4-SEM (a) bulk and (b) magnified image of the precipitate produced from ferrous-containing OPM solution at $\mathrm{pH} 4$ and $90^{\circ} \mathrm{C}$

Table VI

Elemental compositions of phases identified in Figure 4

\begin{tabular}{|c|c|c|c|c|c|c|c|}
\hline & $\mathrm{Fe}(w \mathrm{w} \%)$ & $\mathrm{O}$ (wt\%) & S (wt \%) & $\mathrm{Cl}(w \mathrm{t} \%)$ & Ru (wt \%) & Rh (wt \%) & Ir (wt \%) \\
\hline $\begin{array}{l}\text { Dense Fe oxide } \\
\text { Medium dense Fe oxide } \\
\text { Bulk Fe oxide }\end{array}$ & $\begin{array}{c}55.3 \pm 0.4 \\
56.2 \pm 0 \\
55.1 \pm 0.4\end{array}$ & $\begin{array}{c}44.7 \pm 0.2 \\
38.2 \pm 0 \\
37.8 \pm 0.2\end{array}$ & $\begin{array}{l}1.9 \pm 0.1 \\
1.9 \pm 0.1\end{array}$ & $\begin{array}{c}0.3 \pm 0 \\
0.3 \pm 0.1\end{array}$ & $1.5 \pm 0.2$ & $1.4 \pm 0.2$ & $1.2 \pm 0$ \\
\hline
\end{tabular}




\section{Characterization of precipitate formed during the removal of iron}

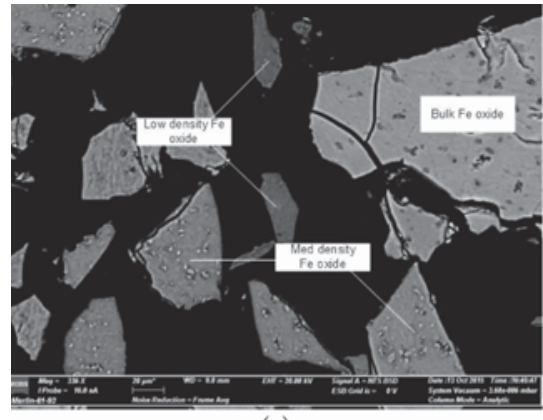

(a)

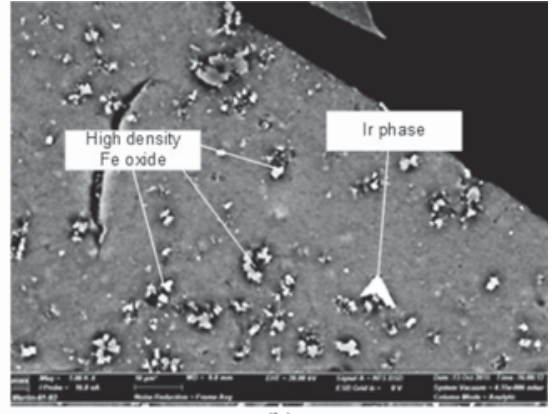

(b)

Figure 5-SEM (a) bulk and (b) magnified image of the precipitate produced from ferric-containing OPM solution at $\mathrm{pH} 4$ and $90^{\circ} \mathrm{C}$

Table VII

Elemental compositions of phases identified in Figure 5

\begin{tabular}{|c|c|c|c|c|c|c|c|}
\hline & $\mathrm{Fe}(w t \%)$ & $\mathrm{O}(w t \%)$ & S (wt \%) & $\mathrm{Cl}(w t \%)$ & Ir (wt\%) & As (wt\%) & $\mathrm{Na}(\mathrm{wt} \%)$ \\
\hline $\begin{array}{l}\text { Bulk Fe oxide } \\
\text { Low density Fe oxide } \\
\text { Med density Fe oxide } \\
\text { High density Fe oxide } \\
\text { Ir phase }\end{array}$ & $\begin{array}{c}53.6 \pm 2.1 \\
51.3 \pm 1 \\
47.5 \pm 0.5 \\
37 \pm 2.5 \\
4.5 \pm 0.4\end{array}$ & $\begin{array}{c}38.7 \pm 0.9 \\
40.5 \pm 0.5 \\
43.1 \pm 0.3 \\
47.6 \pm 1.3 \\
2.5 \pm 0.4\end{array}$ & $\begin{array}{c}3 \pm 1 \\
4.5 \pm 0.6 \\
6.3 \pm 0.3 \\
9.2 \pm 1.4\end{array}$ & $12.2 \pm 2.3$ & $80.7 \pm 2.3$ & $\begin{array}{l}3.7 \pm 0.2 \\
3.1 \pm 0.2 \\
3.1 \pm 0.1 \\
2.6 \pm 0.3\end{array}$ & $\begin{array}{l}0.3 \pm 0.2 \\
1.8 \pm 0.2\end{array}$ \\
\hline
\end{tabular}

precipitation from ferrous-containing nickel sulphate solution at pH 4 and $70^{\circ} \mathrm{C}$ are shown in Figure 6 . The bulk phase consisted of two intergrown grain-like phases. Iridium phases were observed, and other homogeneous iron oxides also formed. The grain-like particles were brittle and readily broke under the electron beam.

Table VIII presents the elemental compositions of the identified phases. When other elements are excluded, the $\mathrm{Fe}: 0$ ratio is $71: 29$; thus, if the stoichiometric ratio is considered in isolation, the predominant phases were predicted to be goethite/haematite-based. Relatively high and consistent OPM levels were observed for all the iron oxide phases; this could possibly be ascribed to the relatively small amount of iron precipitate formed. The lighter grains

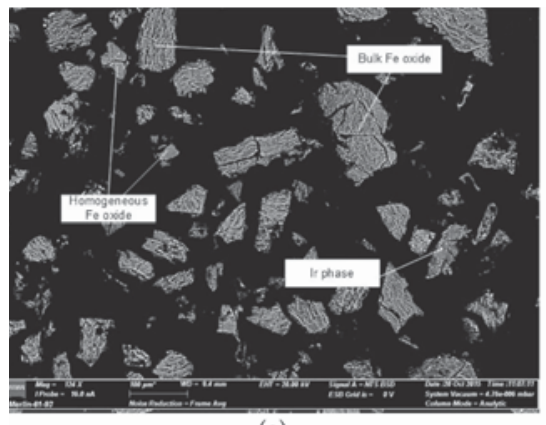

(a) contained slightly less OPMs but more arsenic and nickel than the darker grains. Arsenic inclusion did not lead to varying $\mathrm{Fe}: 0$ ratios and thus it did not necessarily affect the phase mineralogy, apart from co-precipitation.

\section{Seeded precipitates}

XRD analysis of the precipitates produced during seeded precipitation from ferric-containing nickel sulphate solutions showed that no iron phases other than goethite were formed. In the case of the high total metal concentration $(89.3 \mathrm{~g} / \mathrm{L} \mathrm{Ni})$ solution, nickel sulphate was detected in the precipitate, suggesting that scavenging of nickel occurred. The same was not evident for the precipitate produced from the low total metal concentration $(62.5 \mathrm{~g} / \mathrm{L} \mathrm{Ni})$ solution.

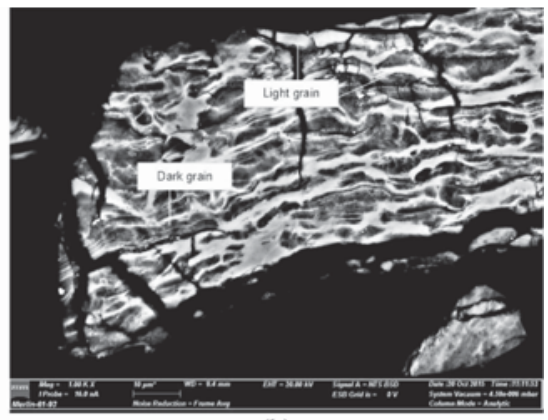

(b)

Figure 6-SEM (a) bulk and (b) magnified image of the precipitate produced from ferrous-containing solution without seeding at pH 4 and $70^{\circ} \mathrm{C}$

Table VIII

Elemental compositions of phases identified in Figure 6

\begin{tabular}{|c|c|c|c|c|c|c|c|c|c|}
\hline & $\mathrm{Fe}(\mathrm{wt} \%)$ & $\mathrm{O}(w t \%)$ & S (wt\%) & Cl (wt $\%)$ & $\mathrm{Ru}(\mathrm{wt} \%)$ & $\mathrm{Rh}(w t \%)$ & $\operatorname{Ir}(w t \%)$ & $\mathrm{Ni}(w \mathrm{t} \%)$ & As (wt\%) \\
\hline $\begin{array}{l}\text { Darker grain } \\
\text { Lighter grain } \\
\text { Homo. Fe-oxide } \\
\text { Ir phase }\end{array}$ & $\begin{array}{c}59.2 \pm 0.3 \\
58.6 \pm 0.4 \\
59.1 \pm 6.1 \\
3.5 \pm 0.5\end{array}$ & $\begin{array}{c}23.6 \pm 0.1 \\
24.1 \pm 0.2 \\
24.1 \pm 0.8 \\
14 \pm 0.1\end{array}$ & $\begin{array}{c}1.1 \pm 0.1 \\
1.4 \pm 0.1 \\
1.2 \pm 1\end{array}$ & $4.4 \pm 1.8$ & $\begin{array}{c}2 \pm 0.1 \\
1.4 \pm 0.4 \\
1.1 \pm 0.4\end{array}$ & $\begin{array}{c}1.7 \pm 0 \\
0.4 \pm 0.4 \\
0.6 \pm 0.4\end{array}$ & $78 \pm 2.9$ & $\begin{array}{l}2.3 \pm 0.2 \\
2.6 \pm 0.1 \\
3.6 \pm 6.2\end{array}$ & $\begin{array}{c}9.6 \pm 0.1 \\
10.8 \pm 0.2 \\
9.5 \pm 0.4\end{array}$ \\
\hline
\end{tabular}




\section{Characterization of precipitate formed during the removal of iron}

The SEM images of the precipitate formed by seeded precipitation from the ferric-containing solution (Figure 7) suggested that growth occurred on the seeding material. This was evident from the denser phase observable on the particle surface boundary, the relatively similar appearance of all particles in Figure $7 \mathrm{a}$ (there are no particles with clearly noticeable differences in densities or phases), as well as the shape of the crystals. The elemental composition of the seed phase reported in Table IX is in agreement with the composition of goethite. The elemental composition of the higher density inclusions (bright inclusions in Figure 7) indicates a higher oxygen to iron ratio than in the goethite seed material. These inclusions were attached to the bulk goethite particle, but might have been independently precipitated prior to agglomeration.

\section{Conclusions}

The effect of process conditions on the characteristics of iron precipitates formed from ferric and ferrous sulphate solutions was investigated, with specific attention to 'other precious metal' (OPM: Ru, Rh, and Ir) behaviour. While no changes in the PSD were observed during seeded precipitation from ferrous solutions, seeded precipitation from ferric solutions resulted in particle growth and, therefore, particles significantly larger than the goethite seed material. Increasing the $\mathrm{pH}$ from 2.5 to 4 during precipitation from ferric solutions resulted in an increase in the total BET surface area of the precipitate. This was ascribed to a more amorphous surface area which formed as a result of more rapid iron precipitation and poor ordering of crystal structure.

A wide variety of iron precipitation products were observed in the study, which were all best described under the ferrihydrite and schwertmannite umbrella. Iron oxide phases of varying iron, oxygen, and sulphate content were predominant. Increasing the $\mathrm{pH}$ from 2.5 to 4 generally resulted in more homogenous iron oxide phases in the precipitate. Goethite seeding induced targeted precipitation,

Table IX

\section{Elemental compositions of phases identified in}

Figure 7

\begin{tabular}{|l|c|c|c|}
\hline & $\mathbf{F e}(\mathbf{w t} \%)$ & $\mathbf{O}(\mathbf{w t} \%)$ & $\mathbf{S}(\mathbf{w t} \%)$ \\
\hline Denser Fe oxide & $51.4 \pm 2.7$ & $46.7 \pm 2.7$ & $1.2 \pm 0.2$ \\
Goethite seed & $64.7 \pm 0.5$ & $35.1 \pm 0.1$ & $0.2 \pm 0.1$ \\
\hline
\end{tabular}

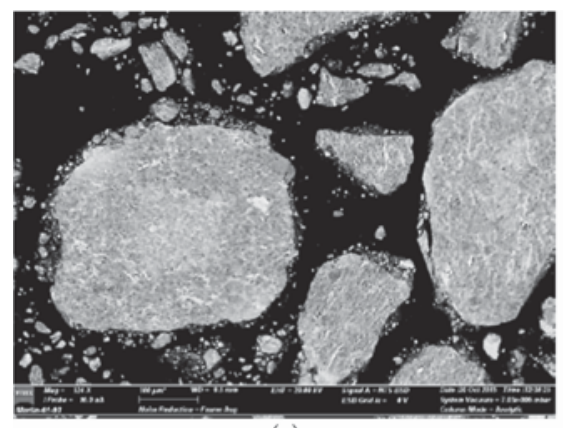

(a) resulting in goethite forming as the only iron species and limited OPM precipitation. Ruthenium and rhodium were only observed in low quantities within iron oxide compounds. These iron compounds were distinguishable yet variable. Iridium tended to precipitate without the inclusion of iron or other OPMs. The iridium precipitation product was complexed with chloride and oxygen in variable amounts. The iridium compound then served as a site for heterogeneous nucleation and growth of the bulk iron oxides.

\section{References}

BazilevSKAya, E., Archibald, D.D., and Martínez, C.E. 2012. Rate constants and mechanisms for the crystallization of Al nano-goethite under environmentally relevant conditions. Geochimica et Cosmochimica Acta, vol. 88. pp. 167-182. http://doi.org/10.1016/j.gca.2012.04.026

Bigham, J.M., SchWertmann, U., Traina, S.J., Winland, R.L., and Wolf, M. 1996. Schwertmannite and the chemical modeling of iron in acid sulfate waters. Geochimica et Cosmochimica Acta, vol. 60, no. 12. pp. 2111-2121. http://doi.org/10.1016/0016-7037(96)00091-9

CoRnell, R.M. and Schwertmann, U. 2003. The Iron Oxides: Structure, Properties, Reactions, Occurences and Uses. 2nd edn. Wiley.

DAs, S., HendRY, M.J., and EssiLfIE-Dughan, J. 2011. Transformation of two-line ferrihydrite to goethite and hematite as a function of $\mathrm{pH}$ and temperature. Environmental Science and Technology, vol. 45, no. 1. pp. 268-275. http://doi.org/10.1021/es101903y

DutRIZAC, J.E. 1980. The physical chemistry of iron precipitation in the zinc industry. Proceedings of Lead-Zinc-Tin '80. The TMS-AIME World Symposium on Metallurgy and Environmental Control, Las Vegas, Nevada. Cigan, J.M., Mackey, T.S., and O'Keefe, T.J. (eds). The Metallurgical Society of AIME, New York. pp. 532-564.

GoLDschmidT, V.M. 1937. The principles of distribution of chemical elements in minerals and rocks. Journal of the Chemical Society, pp. 655-673. http://doi.org/10.1039/JR9370000655

JiAnG, H. and Lawson, F. 2006. Reaction mechanism for the formation of ammonium jarosite. Hydrometallurgy, vol. 82, no. 3-4. pp. 195-198. http://doi.org/10.1016/j.hydromet.2006.03.013

Lowson, R.T. 1982. Aqueous oxidation of pyrite by molecular oxygen. Chemical Reviews, vol. 82, no. 5. pp. 461-493. http://doi.org/10.1021/cr00051a001

Rovquerol, J., Avnir, D., Fairbridge, C.W., Everett, D.H., Haynes, J.H., Pernicone, N., Ramsay, J.D.F., Sing, K.S.W., and Unger, K.K. 1994. Recommendations for the characterization of porous solids. Pure and Appl. Chemistry, vol. 66, no. 8. pp. 1739-1758. http://doi.org/doi:10.1351/pac199466081739

Schwertmann, U. and CARLSON, L. 2005. The pH-dependent transformation of schwertmannite to goethite at $25^{\circ} \mathrm{C}$. Clay Minerals, vol. 40 , no. 1 . pp. 63-66. http://doi.org/10.1180/0009855054010155

Singer, P.C. and STUmm, W. 1970. Acidic mine drainage: the rate determining step. Science, vol. 167, no. 3921. pp. 1121-1123.

YU, J.Y., РАRK, M., and KIM, J. 2002. Solubilities of synthetic schwertmannite and ferrihydrite. Geochemical Journal, vol. 36, no. 2. pp. 119-132. http://doi.org/10.2343/geochemj.36.119

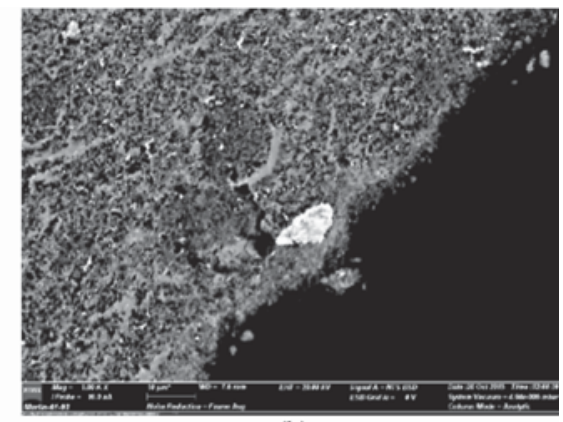

(b)

Figure 7-SEM (a) bulk and (b) magnified image of the precipitate produced from ferric-containing solution with seeding at $\mathrm{pH} 4$ and $90^{\circ} \mathrm{C}$ 